\title{
BRAND LOYALTY MODEL FOR ORAL CARE AND LIFE INSURANCE SECTOR
}

\author{
${ }^{1}$ Dr. J. K. Raju \& ${ }^{2}$ Mr. Manoj Pandey
}

\begin{abstract}
Brands require continuous innovation to keep them relevant else they risk falling in the market's "silence zone". One of the most popular strategies to keep a brand relevant is through differentiation as emphasized by many researchers in this field. Brand differentiation can be built based on a combination of attributes such as uniqueness, customer service, value for money, emotional bonding, and reliability. Brand differentiation helps in creating brand identity which is an important driver for brand loyalty. The present research is focused on investigating attributes for brand success and developing a brand loyalty model for Life Insurance Sector (service category) and Oral Care Sector (product category) in Indian context. The idea is to explore brand attributes which are closely associated with brand success and then perform regression analysis to investigate brand loyalty. Model limitation, suggestions, and conclusion are also discussed.
\end{abstract}

Keywords : Brand Perception, Brand Attributes, Brand Uniqueness, Brand Loyalty

\section{INTRODUCTION}

Brand loyalty, in marketing, consists of a consumer's commitment to repurchase or otherwise continue using the brand and can be demonstrated by repeated buying of a product or service or other positive behaviors such as word of mouth advocacy.

Brand loyalty is more than simple repurchasing, however. customers may repurchase a brand due to situational constraints (such as supplier lock-in), a lack of viable substitutes, or out of convenience. Such loyalty is referred to as "limited loyalty" (David and Sharon, 2002). True brand loyalty exists when customers have a high relative attitude toward the brand which is then exhibited through repurchase behavior (Alan and Basu, 1994). This type of loyalty can be a great asset to the firm: customers are willing to pay higher prices, they may cost less to serve, and can bring new customers to the firm.
For example, if a customer has brand loyalty to Company A, he will purchase Company A's products even if Company B's are cheaper and/or of a higher quality. An example of a major brand loyalty program that extended for several years and spread throughout the country is Life Insurance Corporation of India (LIC). Perhaps the most significant contemporary global example of brand loyalty is the

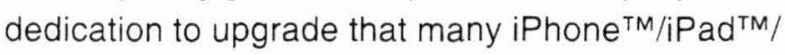
iPod $^{\mathrm{TM}}$ users show towards Apple (company) and its products.

Some of the challenges brand-executives are facing today relates to building and sustaining brand loyalty. To strengthen brand loyalty, apart from time, commitment, and running various loyalty programs, what other measures brand managers can undertake? How are concepts such as Social, Location, and Mobile (SoLoMo) relevant to brand loyalty?

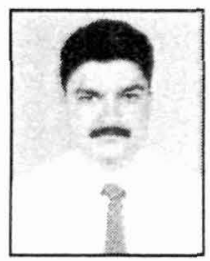

\footnotetext{
Dr. J.K. Raju, B.E., MBA, PhD

Associate Professor,

Institute of Management Studies,

Kuvempu University, P.G. Center

Davangere, Karnataka
}

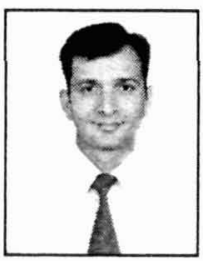

Mr. Manoj Pandey

PhD Research Scholar,

Kuvempu University, P.G. Center,

Davangere, Karnataka 
One of the important features of a brand is its identity. It is essential that a brand should have an identity which can resonate well with its target customer and reflect the core competency of its firm's products and services. This identity can then become the launch pad for advertising to focus on positioning and differentiation. However with too many products and services, strong brands can fight brand symmetry (when all brands are perceived similar) and has the potential to stand out amongst competitors.

For a brand to remain relevant there are several active ingredients:

1. Ensuring the brand remains consistent with its image internally and externally which could require continuous nurturing

2. Warranting same customer experience at every touch point (from advertising to firm's website, letters and promotions, interaction with sales team and customer care).

3. Emphasizing internal brand marketing

4. Assuring high customer experience in all channels.

Companies very often acknowledge the importance of excellent customer service but when it comes to delivering, they fail. Customers often are unhappy with the response they get for their needs or queries either through email or phone. The email or phone response often lacks complete information which can solve customer problem. One of the popular Customer Satisfaction Index survey in USA (conducted on a regular basis since 1994) shows that companies have not been able to improve customer service over the past decade (refer Figure 1).

Figure 1: Customer Satisfaction Index for USA

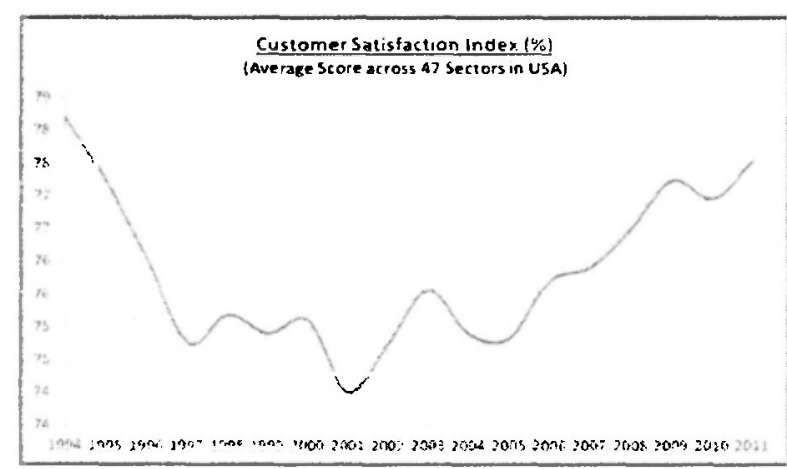

Source: $h t t p: / / w w w . t h e a c s i . o r g$
One of the most significant attribute of brand differentiation is customer service (Johnson and Garbarino, 1999). This further reinforces customer satisfaction. An all round customer satisfaction at various touch points further enhances brand loyalty. Apart from customer service, attributes such as product reliability, innovation, uniqueness (Kevin, 2005) and meeting customer expectations also plays an important role in brand differentiation. If companies only focus is product and services then they are doomed to fail. Today is the era of relationship. Apple, known for its innovative products and services are aware that innovation in technology is quite transient. Competition will catch up one day (read as Sasmung) who are building the next generation of products backed-up by excellent customer service and relationship.

Another case is India's automobile sector. Mature players in the market have build excellent relationship with their customer segments which helps them build the next generation of cars. They understand that Indian customer segments are getting younger. The average age of a new car buyer is 31 years as compared to 39 years a decade ago. The car market has evolved from compact car to premium hatchbacks to SUVs. In Jan 2012 auto show at Delhi, many car makers showcased mini-SUVs for the Indian market. The initial response was excellent and now all major players are busy finalizing their production schedule and launch dates for these mini-SUVs. This is all about market and customer relationship. Building customer relationship has a direct correlation with developing brand loyalty. Loyalty gets further reinforced when customer gets emotionally involved with the brand.

In early 90's, Dow Jones developed a campaign to promote Wall Street Journal. The promotion said "A brand or corporate image is not something that can be seen, touched. tasted, defined or measured. Intangible and abstract. it exists solely as an idea in the mind. Yet it is often a company's most precious asset......in a world of parity products and services, nothing can tilt things more dramatically in your favor". Following are the distinct advantages of a strong brand: 
- They are perceived to be different from their competitors.

- They are able to satisfy the customers emotionally and intellectualiy.

- They are reliable and deliver on their promise.

When brands operate at this level, they are easily able to resonate with customers which help in building a powerful emotional relationship. This is the key to loyalty. There is no other shortcut.

\section{STATEMENT OF THE PROBLEM}

No marketing manager would like their brand to be seen as a commodity. In fact the whole concept of marketing is based on creating profitable brands through differentiation. Understanding attributes leading to brand success is the construct with loyalty being one of the concepts. It is hence imperative that the brand managers should have a practical tool to measure brand loyalty in comparison to their competitor brands. With the knowledge of relative brand loyalty, brand manager can take appropriate actions to rebuild on loyalty attributes. Considering that in mind, the research is focused on developing a model for measuring relative brand loyalty.

\section{OBJECTIVES OF THE STUDY}

The main objectives of the study are:

1. To understand, review and define the attributes for 'Brand Success'

2. To develop and validate the concept and algorithm for Brand Loyalty Model

3. To discuss the survey results and provide relevant suggestions and conclusion

The research is conducted in two phases:

- The first survey is conducted to study which brand attributes are more important in determining brand success. The idea is to group similar brand attributes together and converge on a list of smaller number of attributes for second survey. The sample size was 200 (academicians at management colleges) with a response rate of $72 \%$.
- The second survey was conducted to study the brand loyalty across two sectors. The selected attributes from survey one was used for survey two. The sample size was 500 consumers comprising of students/ employed/housewives/businessmen with a response rate of $79 \%$.

\section{SCOPE OF THE STUDY}

The scope is limited to the following two sectors: Life Insurance and Oral Care (one each from Product and Service category). Brands limited to the following:

Table 1: Sector, Brand Code and Brand Name

\begin{tabular}{|l|c|l|}
\hline Sector & Brand Code & Brand Name \\
\hline Life Insurance & 1 & LIC \\
\hline Life Insurance & 2 & ICICI Prudential \\
\hline Life Insurance & 3 & SBI Life \\
\hline Life Insurance & 4 & HDFC Standard Life \\
\hline Life Insurance & 5 & Bajaj Allianz \\
\hline Life Insurance & 6 & Birla Sunlife \\
\hline Life Insurance & 7 & Max New York Life \\
\hline Oral Care & 1 & Colgate \\
\hline Oral Care & 2 & Close-up \\
\hline Oral Care & 3 & Pepsodent \\
\hline Oral Care & 4 & Dabur Red \\
\hline Oral Care & 5 & Vicco \\
\hline Oral Care & 6 & Cibaca \\
\hline
\end{tabular}

(Source: Survey Scope)

Survey Area: Bangalore city (being cosmopolitan, generalization of research results would be easier across segments and markets). The intent of the study is to develop the loyalty model and validate the algorithm/modeling process. The Loyalty score computed for a brand is at one point in time and replicating the study may not give the same score again.

\section{LIMITATIONS OF THE STUDY}

It is important to mention that the scope of this study only focused on investigating the relationship between customer attributes and brand loyalty (though a very important one). The study is limited to the loyalty perception of sampled customers only. The research 
however does not reject other possible links between specific attributes or combination of attributes and customer behaviour. For example: Customers may give higher priority to some attributes than others in deciding their choice and response.

For generalization of the research, it is recommended to replicate and extend the model across a broad range of products and markets (including urban and rural) especially in the area of Consumer Packaged Goods (CPG). This is important considering the paper 'The measurement \& dimensionality of brand associations' by Lamb and Low (2000) in which it is argued that level of brand knowledge and experience may contribute to deviation in results across different product categories.

\section{DATAANALYSIS}

\section{A. SURVEY ONE}

Clustering technique was used to select the key attributes for Brand Success. The max Cluster criteria (or max Eigen value) can be adjusted as per the research requirements. For this research the max Cluster criteria was set at seven to ensure manageable set of heterogeneous clusters are created. SAS procedure 'PROC VARCLUS' with Centroid method produced seven variable clusters (constructs) which explained $65.2 \%$ of the variation. SAS output and summary of the Centroid Method is shown in Figure 2.

Figure 2: Variable Cluster - SAS output for the Centroid Method

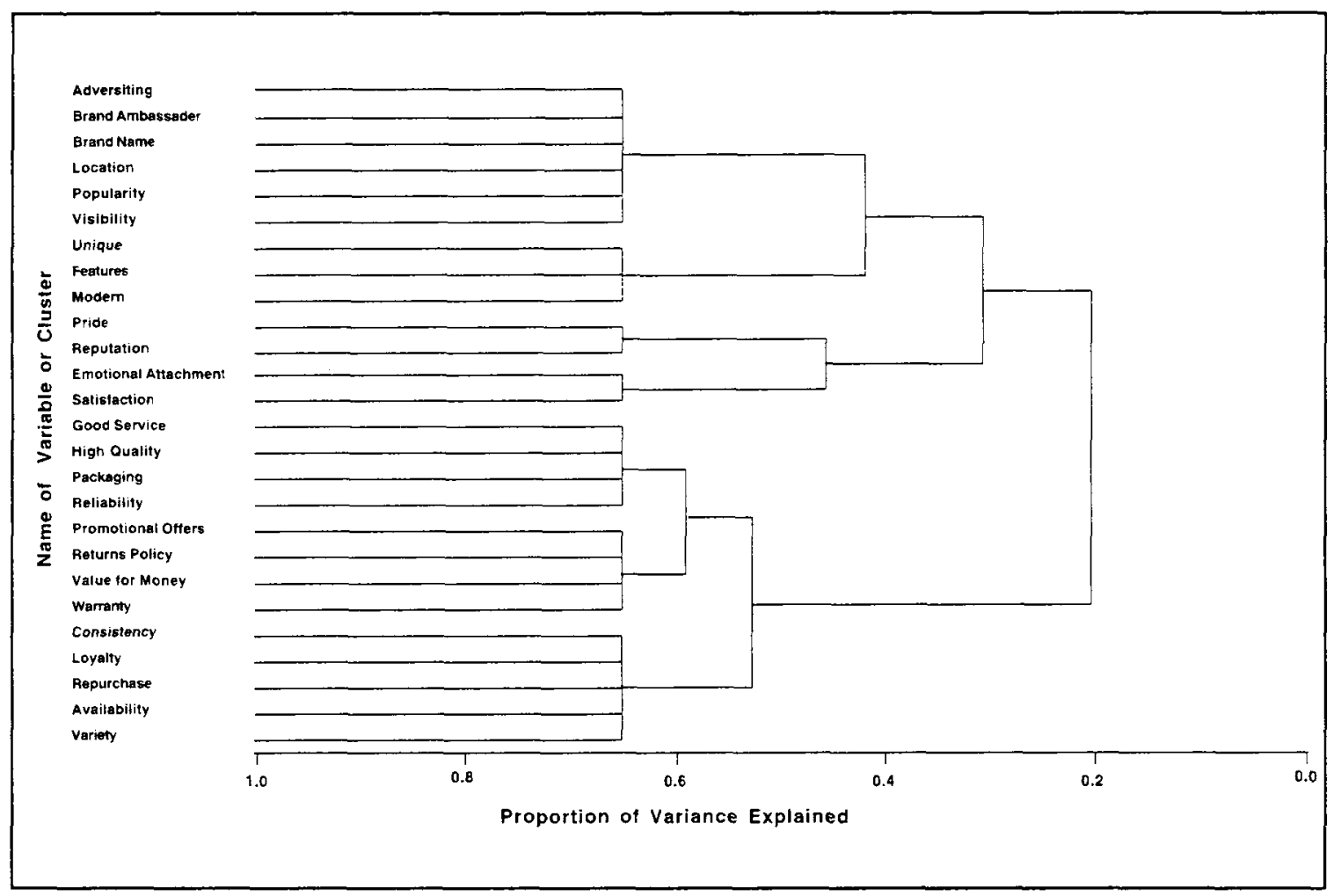

(Source: Survey Analysis)

The seven constructs were again validated by using Exploratory Factor Analysis (EFA), refer Table 2. Highlighted in green are the association between
Factors and Attributes. For example Advertising is associated with Factor 1 (highest factor loading of 0.74 ). 
Table 2: EFA - Rotated Factor Pattern (Standardized Regression Coefficients)

\begin{tabular}{|c|c|c|c|c|c|c|c|}
\hline \multirow[b]{2}{*}{ Brand Aftributes } & \multicolumn{7}{|c|}{ Factors } \\
\hline & Factor 1 & Factor 2 & Factor 3 & Factor 4 & Factor 5 & Factor 6 & Facior 7 \\
\hline Advertising & 0.74 & -0.01 & -0.01 & 0.03 & 0.02 & -0.02 & 0.16 \\
\hline Brand Ambassader & 0.79 & 0.15 & -0.14 & -0.15 & -0.09 & -0.05 & 0.12 \\
\hline Uniaue & 0.25 & -0.06 & 0.05 & 0.01 & -0.16 & -0.11 & 0.25 \\
\hline Brand Name & 0.53 & -0.07 & 0.07 & 0.14 & 0.06 & -0.13 & -0.11 \\
\hline Festures & 0.38 & -0.16 & -0.09 & 0.16 & 0.13 & 0.03 & 0.43 \\
\hline Emotional Attachment & -0.05 & 0.00 & -0.01 & -0.02 & 0.00 & 0.85 & 0.03 \\
\hline Consistency & -0.02 & 0.84 & 0.02 & -0.01 & 0.03 & -0.07 & .0 .06 \\
\hline Good Service & 0.04 & 0.07 & 0.77 & 0.00 & 0.01 & -0.09 & -0.03 \\
\hline High Ouslity & 0.05 & 0.07 & 0.87 & -0.03 & -0.01 & -0.05 & .0 .04 \\
\hline Location & 0.50 & 0.24 & -0.08 & .0 .10 & -0.05 & 0.00 & -0.07 \\
\hline Loyaity & -0.03 & 0.61 & 0.09 & -0.07 & -0.05 & 0.01 & 0.46 \\
\hline Modern & 0.53 & -0.11 & 0.29 & -0.11 & -0.03 & 0.07 & 0.11 \\
\hline Packaging & -0.06 & -0.07 & 0.54 & 0.10 & 0.00 & 0.01 & 0.10 \\
\hline Popularity & 0.72 & 0.03 & 0.03 & 0.07 & 0.00 & 0.03 & 0.23 \\
\hline Pride & 0.02 & 0.00 & -0.04 & .0 .02 & 0.87 & 0.00 & -0.01 \\
\hline Promotional Offers & 0.04 & 0.04 & 0.05 & 0.71 & -0.04 & -0.10 & .0 .01 \\
\hline Reliablility & 0.00 & 0.05 & 0.09 & 0.17 & 0.02 & 0.12 & 0.01 \\
\hline Repurchase & 0.09 & 0.53 & 0.12 & -0.02 & -0.01 & 0.00 & 0.51 \\
\hline Reputation & -0.02 & 0.05 & 0.05 & .0 .08 & 0.88 & -0.03 & 0.07 \\
\hline Relurns Policy & -0.05 & .0 .05 & 0.12 & 0.74 & 0.05 & -0.02 & 0.14 \\
\hline Satisfaction & 0.06 & 0.01 & 0.01 & -0.03 & -0.02 & 0.86 & -0.04 \\
\hline Avallability & 0.08 & 0.83 & -0.02 & 0.10 & 0.09 & 0.00 & -0.03 \\
\hline Value for Money & -0.04 & 0.25 & -0.14 & 0.83 & -0.03 & 0.04 & 0.06 \\
\hline Variety & 0.12 & 0.70 & 0.00 & 0.10 & -0.02 & 0.08 & -0.09 \\
\hline Visibllity & 0.41 & 0.01 & 0.12 & 0.11 & 0.06 & 0.15 & -0.15 \\
\hline Warranty & 0.02 & -0.05 & 0.13 & 0.52 & -0.13 & 0.00 & -0.05 \\
\hline
\end{tabular}

(Source: Survey Analysis)

The factor loading are displayed in the Figure 3 below:

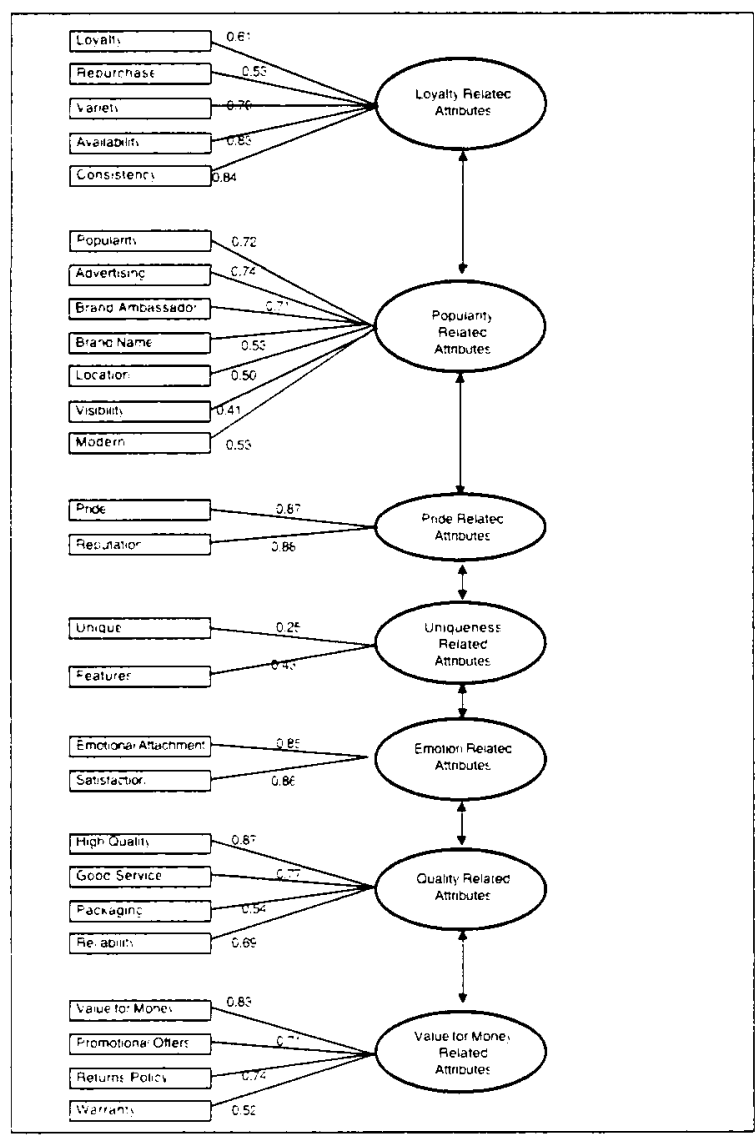

(Source: Survey Analysis) 
The factors are weakly correlated with each other (correlation coefficient $<0.5$ ). This indicates that the factors are independently responsible for the item distribution they represent. It also denotes absence of multicollinearity ${ }^{4}$.

An attempt was made to confirm the above model using Confirmatory Factor Analysis (CFA) using PROC CALIS procedure in SAS. CFA couldn't confirm the seven cluster model and one of the reasons attributed to it is small sample size (143 in this case). As per Bearden and Sharma (1982), the Normed Fit Index (NFI) of CFA model which analyzes the discrepancy between the chi-squared value of the hypothesized model and the chi-squared value of the null model was found to be very susceptible to sample size.

Final set of constructs used for Survey Two are:

- Popularity

- Loyalty
- High Quality

- Value for Money

- Pride

- Emotional Attachment

- Unique

- Familiarity - This variable has been added by the researcher to incorporate consumer's knowledge about the brand to improve the response quality

\section{A. SURVEY TWO}

\section{i. REGRESSION-SECTOR LEVEL}

Regression was performed at sector level to analyze the predictive power of attributes in predicting loyalty. The output including the Regression Equation, R Square, and VIF is discussed below :

Insurance Sector

Table 3: Correlation of Estimates (regression on loyalty) - Insurance Sector

\begin{tabular}{|l|c|c|c|c|c|c|c|c|}
\hline \multicolumn{10}{|c|}{ Correlation of Estimates } \\
\hline Variable & Intercept & Familiarity & Unique & VFM & Popularity & Pride & High Quality & E-motion \\
\hline Intercept & 1.00 & -0.32 & -0.10 & -0.23 & -0.12 & -0.17 & -0.22 & -0.18 \\
\hline Familiarity & -0.32 & 1.00 & -0.09 & -0.04 & -0.14 & -0.09 & -0.16 & -0.06 \\
\hline Unique & -0.10 & -0.09 & 1.00 & -0.17 & -0.13 & -0.11 & -0.15 & -0.12 \\
\hline VFM & -0.23 & -0.04 & -0.17 & 1.00 & -0.10 & -0.10 & -0.13 & -0.13 \\
\hline Popularity & -0.12 & -0.14 & -0.13 & -0.10 & 1.00 & -0.10 & -0.21 & -0.12 \\
\hline Pride & -0.17 & -0.09 & -0.11 & -0.10 & -0.10 & 1.00 & -0.11 & -0.22 \\
\hline High Quality & -0.22 & -0.16 & -0.15 & -0.13 & -0.21 & -0.11 & 1.00 & -0.08 \\
\hline Emotion & -0.18 & -0.06 & -0.12 & -0.13 & -0.12 & -0.22 & -0.08 & 1.00 \\
\hline
\end{tabular}

(Source: Survey)

${ }^{1}$ Case of multiple regression in which the independent attributes are themselves highly correlated 
Interpretation :

- All the attributes were significant at $p<0.0001$.

- The forecasting equation is: Loyalty $=0.511+0.3692$ Familiarity +0.1216 Unique +0.1456 VFM +0.2111 Popularity +0.0894 Pride +0.1157 High Quality +0.0702 Emotion

- Variable Inflation Factor (VIF) for all the attributes was less than 10 indicating absence of multicollinearity between them (Kutner, 2004). This is further supported by Correlation of Estimates (highest value being -0.32 ) in Table 3.

- Adjusted R-Squared is 0.312 indicating low predictive power of the forecasting equation but can be accepted considering heterogeneity in the sample. No patterns wereobserved in the residuals suggesting model equation holding good.

\section{Oral Care}

Table 4: Correlation of Estimates (regression on loyalty) - Oral Care Sector

\begin{tabular}{|l|c|c|c|c|c|c|c|c|}
\hline \multicolumn{10}{|c|}{ Correlation of Estimates } \\
\hline Variable & Intercept & Familiarity & Unique & VFM & Popularity & Pride & High Quality & E-motion \\
\hline Intercept & 1.00 & -0.42 & -0.06 & -0.19 & -0.10 & -0.17 & -0.21 & -0.18 \\
\hline Familiarity & -0.42 & 1.00 & -0.09 & -0.10 & -0.10 & -0.09 & -0.07 & -0.06 \\
\hline Unique & -0.06 & -0.09 & 1.00 & -0.24 & -0.15 & -0.11 & -0.12 & -0.16 \\
\hline VFM & -0.19 & -0.10 & -0.24 & 1.00 & -0.13 & -0.10 & -0.09 & -0.11 \\
\hline Popularity & -0.10 & -0.10 & -0.15 & -0.13 & 1.00 & -0.10 & -0.25 & -0.08 \\
\hline Pride & -0.10 & -0.11 & -0.11 & -0.08 & -0.17 & 1.00 & -0.16 & -0.19 \\
\hline High Quality & -0.21 & -0.07 & -0.12 & -0.09 & -0.25 & -0.11 & 1.00 & -0.11 \\
\hline Emotion & -0.18 & -0.06 & -0.16 & -0.11 & -0.08 & -0.22 & -0.11 & 1.00 \\
\hline
\end{tabular}

(Source: Survey)

\section{Interpretation:}

- All the attributes were significant at $p<0.0001$.

- The forecasting equation is:

Loyalty $=0.6167+0.2397$ Familiarity +0.1615 Unique +0.0886 VFM +0.177 Popularity +0.1038 Pride + 0.1081 High Quality +0.1553 Emotion

- Variable Inflation Factor (VIF) for all the attributes was less than 10 indicating absence of multicollinearity between them (Kutner, 2004). This is further supported by Correlation of Estimates (highest value being -0.42) in Table 4.

- Adjusted R-Squared is 0.343 indicating low predictive power of the forecasting equation but can be accepted considering heterogeneity in the sample. No patterns were observed in the residuals suggesting model equation holding good. 
Regression was performed at brand level to analyze the predictive power of attributes in predicting loyalty. The output including the Significant Attributes, R Square, and VIF is discussed below:

Table 5: Summary of Brand Level Regression on Loyalty

\begin{tabular}{|c|c|c|l|c|c|}
\hline Sector & Brand & $\begin{array}{c}\text { Variable Inflation } \\
\text { Factor (VIF) }\end{array}$ & \multicolumn{1}{|c|}{ Significant Attributes } & $\begin{array}{c}\text { Residual Vs } \\
\text { Predicted Plot }\end{array}$ & R Square \\
\hline Insurance & 1 & $<2$ & All significant except Unique & No Pattern & 0.46 \\
\hline Insurance & 2 & $<2$ & Unique, VFM, Pride, High Quality & No Pattern & 0.26 \\
\hline Insurance & 3 & $<2$ & $\begin{array}{l}\text { Familiarity, Unique, VFM, } \\
\text { Popularity, High Quality }\end{array}$ & No Pattern & 0.53 \\
\hline Insurance & 4 & $<2$ & $\begin{array}{l}\text { Unique, VFM, Popularity, Pride, } \\
\text { High Quality }\end{array}$ & No Pattern & 0.31 \\
\hline Insurance & 5 & $<2$ & $\begin{array}{l}\text { Familiarity, Unique, VFM, Popular- } \\
\text { ity, High Quality, Emotion }\end{array}$ & No Pattern & 0.31 \\
\hline Insurance & 6 & $<2$ & Unique, Popularity, Pride, Emotion & No Pattern & 0.19 \\
\hline Insurance & 7 & $<2$ & Familiarity, Popularity & No Pattern & 0.08 \\
\hline Oral Care & 1 & $<2$ & $\begin{array}{l}\text { Familiarity, VFM, Popularity, Pride, } \\
\text { High Quality, Emotion }\end{array}$ & No Pattern & 0.46 \\
\hline Oral Care & 2 & $<2$ & Unique, Popularity, High Quality & No Pattern & 0.38 \\
\hline Oral Care & 3 & $<2$ & $\begin{array}{l}\text { Familiarity, Unique, VFM, } \\
\text { Popularity, High Quality }\end{array}$ & No Pattern & 0.51 \\
\hline Oral Care & 4 & $<2$ & Unique, VFM, Emotion & No Pattern & 0.24 \\
\hline Oral Care & 5 & $<2$ & Unique, Pride, Emotion & No Pattern & 0.18 \\
\hline Oral Care & 6 & $<2$ & Popularity, Emotion & No Pattern & 0.16 \\
\hline
\end{tabular}

(Source: Survey)

Interpretation: For the Insurance and Oral Care Sector Brands, the significant attributes did not have high VIF (i.e. absence of multicoliinearity). Also there was no pattern observed in the Residual Vs the Predicted Plot implying absence of heteroscedasticity. However, Adjusted R-Squared value is observed to be low indicating low predictive power of the forecasting equation at brand level.

The last step of computing the brand loyalty value by entering attribute mean at brand level (or sector level) in the modeling equation has been left to the discretion of the reader.

\section{SUGGESTIONS}

1. One of the key suggestions is that brand manager or customer segment manager should make sure their brand loyalty is measured on a continuous basis. This can be achieved by using the methodology developed through this research. Be it a product or service, the research shows that brands can be measured on their loyalty attribute. The model helps in knowing relative brand loyalty with respect to its peers. This can be achieved by measuring customer perception on following attributes:

$\begin{array}{llll}\text {. } & \text { Familiarity } & \text { Unique } \\ \text {. } & \text { VFM } & \text {. } & \text { Popularity } \\ \text {. } & \text { Loyale } & \text {. } & \text { High Quality } \\ & \text {. } & \text { Emotion }\end{array}$


2. From the research conducted, it was found that all the attributes were significant for the loyalty model in Life Insurance Sector. Life Insurance service category does suffer from commoditization syndrome. It is quite chalieng ing to differentiate services which are similar. However working on attributes such as uniqueness, VFM, quality, emotion and others, the sector can innovate on the differentiation themes. Just aggressive marketing will not be sufficient to sell the product in this segment. In fact aggressive sales campaigns may further irritate the potential future customers. Since the customer stays with the brand for longer period (as the policy maturity period is generally between $5-15$ years), organizations can use this as an opportunity to connect with customer to communicate the brands unique features so that customers are always in the communication loop. Cross-sell and Up-sell opportunities can also be explored during this period.

3. Also from the research conducted, it was found that all the attributes were significant for the loyalty model in Oral Care Sector. Colgate has been pioneer in product innovation in oral care segment. It also successfully positioned its ad 'surakha chakra'. For long there were no active competitors in this segment and Colgate managed to communicate its brand differentiation in the market. Dabur with its ayurvedic and medicinal value proposition was able to differentiate its product offerings. Cibaca with its value for money proposition was able to achieve the differentiation. The segment still has a lot of scope for product innovation to move up in value chain. Liquid wash, brushing at least twice everyday to increase consumption, product ingredients are few areas where the brands can focus on.

4. It is also recommended that brand manager should be working on increasing and maintaining the brand prominence in the minds of their customers; i.e. to enlarge and strengthen the span of the network related to the brand in customer's memory. This strategy focuses on the number of attributes customer links with the brand rather than specific attributes being linked to the brand. It is the 'Quantity' not the 'Quality' which matters here. This gives multiple options to the communication team in designing the message being sent to customers thus providing opportunities for innovation and entertainment.

\section{CONCLUSION}

It is quite evident that brand perceptions are of significant importance to brand managers and advertisers. The brand that can manage this key input to their advantage would end up being successful. Measuring the Brand Loyalty should be the first step towards understanding the brand and its perception in minds of the customer. The brand loyalty model created through this research helps the brand manager to achieve that. With focus on eight attributes and using an algorithm to compute loyalty score, it is now possible to monitor the performance of brand positioning and loyalty on a regular basis.

Organizations have two choices on product strategy: Differentiation strategy or Low cost strategy. Organization in different point in time and situation may pursue different strategies. If the organization decides to pursue differentiation strategy then brand symmetry must be fought by advertising. As suggested by the current study, developing loyalty by working on other brand attributes may be waste of resources if brand symmetry is not controlled. Organization must work on developing unique brand attributes and make customers believe that all brand choices are not the same and there is a difference (LIC communication on volume and value of settlements). In any case, advertising will be needed to create brand differentiation for fighting brand symmetry before creating brand loyalty.

Organization following low cost strategy would like its advertising to focus on creating high brand symmetry thereby sensitizing customers towards price elasticity. The usual advertising line "why pay more when you can get the same for less" actually fosters brand symmetry perception among the 
customers (Cibaca communication on Value for Money). This way the brand loyalty of competitor brands is challenged and the customers are lured towards products with similar attributes but with lower price. Instead of fighting brand symmetry, the organization actually wants to create brand symmetry through advertising to adopt low price strategy for its brand.

Of course, the multi-attribute metric being employed in this study is a basic one which reflects the aggregated belief a customer has towards the brand. Hence it is the power of the customer's attitude and familiarity towards a brand that drives the future behaviour and action. There is an opportunity here to further extend the research to differentiate clearly between 'attitudinal' and 'share of mind' concept to further justify the results presented. More testing is required to confirm if the relationship is impacted by 'brands share of mind' or 'customers attitude towards the brand' or a combination of two concepts to further improve the understanding on how customer perceptions drive future behaviour.

\section{REFERENCES}

Bearden, W. O., Sharma, S., \& Teel, J. E. (1982), 'Sample size effects on chi square and other statistics used in evaluating causal models. Journal of Marketing Research', 19, 425-430.

Dick, Alan S; Kunal Basu (1994), 'Customer Loyalty: Toward an Integrated Conceptual Framework, Journal of the Academy of Marketing Science, Vol. 22 (2), p99-113.

Johnson, M. and Garbarino, E. (1999), 'The different roles of satisfaction, trust and commitment in customer relationships', Journal of Marketing, $p 70-87$.

Jones, Michael A; David L. Mothersbaugh; Sharon E. Beatty (2002), 'Why Customers Stay: Measuring the Underlying Dimensions of Services Switching Costs and Managing Their Differential Strategic Outcomes,' Journal of Business Research, Vol. 55, p441-50.

Kutcher, Kevin (2005), 'Advertising your unique selling proposition', Rural Telecommunications. Vol. 24 Issue 3, p36-40.

Kutner, Nachtsheim, Neter (2004), Applied Linear

Regression Models, 4th edition, McGraw-Hill Irwin. 